\title{
Moral Capital in the Game Field: CONVERSION AND ACCUMULATION
}

\section{Roland Zarzycki*}

\section{Abstract}

The paper recognizes mechanisms of capital conversion among given social games, which allows in turn to explain the process of commodification of morality. Conclusions depicting the structure of relations between the financial and moral capitals are used to analyse two practical examples: the concepts of SDG and CSR. The paper proposes a useful way of addressing phenomena on the borderline of economics and ethics, which allows to formulate further research problems.

Keywords: moral capital, capital conversion, Sustainable Development Goals, Corporate Social Responsibility

Creating the English-language version of the journal "Zoon Politikon" is financed under contract No. 724/P-DUN/2018 from the funds allocated by the Minister of Science and Higher Education for dissemination of science.

*Roland Zarzycki, Ph.D., Collegium Civitas, Warsaw, Poland, mail: roland.zarzycki@civitas.edu.pl ORCID: https://orcid.org/0000-0003-3742-1901 
Introduction

Anything can function as capital. This statement is not speculative; it is a practical conclusion drawn from explaining actual market mechanisms using modern sociological and psychological models. Namely, it is not the type of resource (e.g. financial means, natural resources, knowledge, interpersonal connections) that decides whether we treat this resource as capital, but rather the role it plays in the socioeconomic system. Hence, it is useful to define capital as a resource that (a) is accumulable and (b) the very fact of its accumulation promotes and intensifies further accumulation. The mechanism of financial capital accumulation together with an analysis of the forms of conversion of various types of capital help explain, in turn, why the logic of capitalism along with the accompanying commodification of goods and values constitute a globally dominant tendency that organizes social life.

To more accurately track these processes, we use intuitive insights provided by abstract models and a broad range of empirical studies conducted by Pierre Bourdieu. To this end, in the initial part of the work, we briefly discuss the key concepts of Bourdieu's sociology, such as game or capital. Later on, these concepts become adapted for practical use in the deliberations presented here.

Subsequently, using Maslow's concept of the pyramid of needs, we present a concept of capital conversion between different types of social games. Maslow's pyramid model, highly controversial in itself, does not play a significant or binding role in our deliberations. Of significance is only the intuitive insight that indicates a possibility of reconstructing a concrete relational hierarchy of needs that is specific for a given social group. Because Maslow's original concept included the aspect of universality, further on we will use the term "relative hierarchy of needs".

In this context, we will attempt to define the term "moral capital". The functioning and application of the introduced terminology and 
narratives are explained using two practical examples: the concepts of Millennium Development Goals (MDG), now replaced by Sustainable Development Goals (SDG), and Corporate Social Responsibility (CSR). Both are important for the organization of modern ethical discourse on a global scale.

Finally, this paper considers the social consequences of the diagnosed mechanisms and processes. It also outlines several issues that require further problematisation and more detailed studies, as well as poses several open-ended research questions, including ones about ideology as an element that makes it possible to integrate the cognitive dissonances of social groups, caused by the untranslatability and incommensurability of social games.

This work has three aims. The first one is an attempt to introduce a useful and relatively objective way of describing social phenomena that occur at the interface between economy and ethics. The second is the explication of certain mechanisms that govern broadly understood capital, especially moral capital. The third is preparing the ground for further theoretical and empirical studies, to which the current deliberations are only a prolegomenon.

\section{Capital in the game field}

Many authors have described social phenomena in terms of a game, both in the field of economics (formal mathematical game theory) and in the domain of the social sciences, e.g. in social psychology (Berne 2016), anthropology (Turner 1974) or philosophy (Gadamer 1986). The "game" is adopted as a sort of basic narrative or basic model of individual behaviours, characterized by specification of the rules that determine possible behaviours, actions, attitudes (i.e. moves) of participants, or players. 
Another key property of this kind of modelling is the definition of positive and/ or negative values, or occasionally other values (e.g. the categories of success or failure). This, in turn, becomes the starting point for defining capital. Capital may have the structure of an accumulated resource that has the value of being useful in terms of attaining goals of a given game. It may also in itself be the game's "goal" when a sufficient degree of its accumulation not so much leads to a success in the given game as is tantamount to such success.

In Bourdieu's view, the game is primarily determined by the field where it is played. The field is an established fragment of social structure along with the appropriate set of relational and functional elements, embedded in a specific historical perspective and characterized by a specific dynamic, discernible (among all the aspects and areas of social life) thanks to the specific mechanisms and rules (of the game) that apply within it and structuralise it.

Thus, in order to determine the structural topology of the game field, it is crucial to identify the system of successes, failures, rewards and punishments that function within the given game. This means discovering the mechanisms for reproducing the game, which are subject to social regulation based on reinforcing signals that are more or less universal in character. Examples of popular reinforcing signals include a range of gestures that signal social recognition of an individual's worth, such as a smile, the speech act of thanking, reciprocation, but also more complex actions, such as public praise in the form of an appropriate ceremony.

By way of socialization, individuals acquire individual preferences. However, as Bourdieu aptly points out, this occurs via individualised socialization that shapes habitus, rather than via socialization taking place in a homogeneous manner throughout the entire community (Bourdieu 1998). As Bourdieu notes, to not to fall into the realism of structure, hypostasizing systems of objective relations by transforming 
them into entireties constituted beyond the history of the individual and the group, it is enough and necessary to move from opus operatum to modus operandi, from statistical regularity and algebraic structure to the principle of production of this observed order and to build a theory of practice or, more precisely, a method of generating practices, which is a precondition of experimental science examining the dialectics of the interior and exterior: structures which are constitutive for a particular type of environment and can be empirically captured in the form of regularities related to a socially structured environment, produce habits, systems of permanent dispositions, structured structures predisposed to act as structuring structures (Bourdieu 1984). Thus, the formation of fields and habitus is dynamic and open in character. Along with the evolution of individualised systems of dispositions, the field itself becomes restructured as well.

Thus, drawing upon Bourdieu's sociology, we can characterize any social game by determining its field, within which individuals (equipped with a specific, dynamic habitus) act in accordance with rules determined, on the one hand, objectively by this field, and on the other hand, subjectively through beliefs rooted in their habitus. As Bourdieu writes, the dialectic between the conditions and habitus is the basis of the alchemy transforming the distribution of capital, the system of perceived differences, differentiating properties, and thus the very distribution of symbolic capital, valid capital, familiarized with its objective truth (Ibidem).

Here, capital (understood by Bourdieu in various modalities, primarily as economic, social and cultural capital) represents the sum of socially significant resources of specific types that remain at the subject's actual or potential disposal. In this sense, capital determines the individual's position in the game field, as well as his/her habitus. From the perspective of this paper, it is useful to define capital as a spe- 
cific (because of its structural characteristics) type of resource, in accordance with the proposal formulated at the beginning of the text. Thus on the one hand, structurally, capital is subject to accumulation, which in itself promotes further accumulation, and on the other hand, functionally, it is a vehicle of distinction within a given game. A simple example of such a resource is the ownership of a rented flat: the flat is a source of so-called passive income and simultaneously improves the owner's position in the "game of making money".

The most important organizing element in Bourdieu's model of reflexive sociology is the notion of distinction. In a sense, every economy of values is ultimately an economy of recognition, since recognition is, on the one hand, a form of objectified capital, a kind of "meta-currency", and on the other hand it becomes autotelic, constituting a prerequisite of all distinction and the sublimation of any possible reinforcement. In a sense, the necessary prerequisite that makes individual recognition possible is the very possibility of distinguishing the subject of that recognition (subjective distinction), and in a further step, the possibility of distinguishing the action or attitude of that subject from among the actions and attitudes that are statistically typical or abstractly "defined" (performative distinction).

In other words, it is about the actual or potential difference within the social system of differences, which in the long run translates into a series of consequences, both in the sphere of the field, the individual habitus, and in the sphere of institutional changes or class structure. As Bourdieu also points out, the fundamental distinction transpires in the area where models of legitimate assimilation and reproduction of a given capital predominate (Bourdieu 1984). Namely, it is the very method of acquiring dispositions that determines, in thelong run, the distribution of further distinctions occurring in the game field, which is structured in accordance with the initial set of rules, discourses and trajectories. 
Conversion of capitals

For the purposes of this text, we treat capital as the source and vehicle of distinction within a given game. Importantly, different games are governed by various types of distinction and their corresponding capitals. As Bourdieu observes, homology exists between the various forms and structures of capital. The sources of this homology are at least twofold, because it results both from the convergence of conditions that promote the accumulation of various types of capital, and from the translatability of a given type of capital into the ability to accumulate capital of a different type. In practice, this means that we can identify specific rules governing the exchange of capital acquired in various games (for example, within a sort of meta-game).

Before formulating how the conversion of various types of capital can be interpreted in an abstract manner, we will discuss a certain illustration of this phenomenon, long known in the field of anthropological research. In ethnography, the term "potlatch" refers to a manifestation of the agonistic basis of cultural life in archaic societies. Potlatch (for example, in one of its most typical variants observed among the Kwakiutl tribe) takes the form of a grand festival, during which one of the two participating groups gives the second one a huge number of gifts to demonstrate its strength (Huizinga 2016).

As J ohan Huizinga describes, it is primarily about giving away goods - the host of the ceremony squanders the property of his entire clan; but the second clan, precisely because it takes part in this ceremony, is therefore obliged to arrange the potlatch on an even larger scale under the threat of losing his/ her name, emblem, totems, honour and civil and religious rights (Huizinga 2016). Potlatch also involves acts of destroying goods, which constitute a demonstration of strength and a call for the rival to destroy an even greater amount of goods. These and similar acts (such as the kula exchange, tribal singing, insult contests or bloody 
fights), examples of which can be found in virtually any culture, are not only proof of the social significance of fame or honour, but also an example of how societies naturally developed the ability to convert one type of capital (material resources) into another ("strength").

Thus, as an organic social phenomenon, potlatch may be identified as one of the basic techniques for conversion of material capital. By showing the mechanisms behind the exchange of financial resources and social capital, as well as political influence, between representatives of the elites of various kinds of games played in the United States around the middle of the previous century, Charles Wright Mills (2000) demonstrated in his book The Power Elite how widespread this phenomenon is. Similarly, with the right tactics, today a clever player can capitalise upon financial gains achieved in one game, e.g. "become the most successful investor in Poland", within another game, where moral capital may constitute the currency (e.g. "become philanthropist of the year in Angola"). In this way, the player achieves transgression, transcending the boundaries of a game that for various reasons has ceased to provide a sufficient level of satisfaction.

Typical circumstances in which such transgression takes place involve exhaustion of the potential for reinforcing victories achieved in the "old" game (e.g. as a consequence of a situation where the player thinks "I have achieved everything there was to achieve") and rising interest in the distinction that can be obtained through participation in the "new" game. As needs from successive rungs of the given relative pyramid of needs become satisfied, the specific properties of capital necessary to satisfy the needs from higher rungs change, forcing individuals to move from one social game to another.

The transfer of resources accumulated in previous games to the field of new games seems to be the most rational behaviour, but its very possibility depends on the player's ability to capitalise these resources under the new rules. Typically, higher levels of needs and the more refined 
games correlated with them have more difficult entry thresholds that protect their functioning against "inflation" caused by overly easy and extensive inflow of new capital. For example, not every person who buys chocolate for the hungry or sings a beautiful hymn for those in need will automatically belauded for a good deed. Bourdieu drew attention to the existence of legitimate conditions that govern the acquisition and reproduction of capital, and this precisely is where the validity of these conditions becomes apparent.

The legitimacy of forms of acquisition of moral capital

We would like to designate some of the games that involve moral beliefs as morality games, and the capital that functions within their frames as moral capital. A good opening example is the Christian metaphor of "collecting" good deeds and avoiding sins, an inventory of which is supposedly kept by some sort of heavenly account department. A more scientific version of the same metaphor would probably involve putting the great Other in the role of the monitoring body.

In literature, the concept of moral capital is used more or less explicitly in various contexts. In Jonathan Haidt's The Righteous Mind (2012), moral capital is defined as a resource that supports the functioning of a moral community. J ohn Kane (2001) uses this notion in the sense of a scalable attribute that can be assigned to politicians, placing it in the sphere of image and perception, rather than in the domain of ethics. Piotr Sztompka (2015) describes moral capital as the core of social capital, typical for societies bound by the norms of trust, loyalty, reciprocity, solidarity, respect and justice, and affirming these norms.

Legitimate forms of implementing and adopting specific values, as well as the accumulation of capital (in this case, moral capital), become constituted and take shape on the basis of socially reproduced rules of the game. A similar mechanism operates in the case of cultural capital. 
In this paper, we interpret moral capital in a way that is largely in line with the intuitive insights behind the concepts of Haidt, Kane and Sztompka (even if our interpretation is slightly closer to Bourdieu's general theory), as the actual and potential disposition of the body and mind to behaviours socially recognized as morally good and right, i.e. compliant with the currently valid axiological code (embodied forms); to appropriate reflexivity, sensitivity, education, but also specific ideological and institutional affiliations (institutionalised forms); and to using specific artefacts, treated by the force of the current custom as symptoms of cultivation of the above-mentioned code (objectified forms). By analogy, we recognize the mechanism of capital accumulation via an individual development path and the distinction shaped in this way, which is both the source and the purpose of action. At the sametime, we see no reason to refrain from discussing the moral capital of institutions, or of entire societies, in analogous terms, as Sztompka does.

The distribution of material capital and the mechanisms that govern its distribution severely limit individuals' mobility between relevant social fractions or classes. Similarly, in the case of moral capital, such migrations are largely predetermined by the logic inherent in the trajectories of interclass mobility.

Individual mobility within the game field is impaired by collectively built rationalizations that legitimise given systems of behaviours and values, always accompanied by packages of affirmative, stigmatizing and exclusive practices, which structuralise the processes of reproducing disposition systems. Because a change of position within the fractional system is often associated with the necessity of rejecting the system that legitimises the actions hitherto undertaken by the individual, moral conversion involves acknowledgment of one's own moral error by the subject who achieves the transgression, and this in itself is a factor that 
helps stabilise structure. As Maria Ossowska noted outright in a different context (1971), the system for reproducing and consolidating class divisions is also reflected in the sphere of morality.

A variant of fractionalism thus defined is the phenomenon of moral boundary drawing diagnosed in modern sociology. It consists of a group act of distinction wherein a given group claims that it possesses certain virtues, while simultaneously denying that other groups possess them. Another social factor that structuralizes the fractional system is social shame. On the one hand, it has a homeostatic function within a given fraction or class, but on the other hand, it significantly affects the formation of relationships (trajectories) between fractions and classes. For example, research conducted by MacLeod (1995) proves that young, working-class blacks who believe in the American dream have a greater tendency to feel shame than their white counterparts.

The mechanism of accumulation of moral capital is, in itself, associated with more restrictive social control of this capital. This control focuses, among other things and above all, on aspects such as coherence, authenticity and awareness of actions and attitudes. For example, capital accumulated over many years that manifests itself in the image of a good man and citizen may be easily destroyed with just one politically irresponsible joke or rash action.

Of course, the autonomy of attitude and moral evaluation is a question for broader discussion. When a group denies that an individual possesses certain qualities, to what extent is that individual able to remain convinced that he/ she does possess these qualities, and furthermore, to derive healthy satisfaction from their possession? It is worth mentioning that such independence is related to the individual's potential for emancipation and his/her ability to reach beyond the existing game, or even to independently influence its principles. In the language of Friedrich Nietzsche's philosophy, these characteristics exactly correspond to the qualities of the Übermensch (Nietzsche 2009). 
On a more detailed and operational plane, the social theory of morality developed in a systematic manner would require, on the one hand, research involving identification of the rules and fields of specific, local morality games, and on the other hand, determining the topology of habitus that characterizes the distribution of legitimate tools for the accumulation of social recognition due to the presented moral capital. However, one direct conclusion can already be drawn from viewing the phenomenon of morality in this way; namely, its double perception through the lens of game theory.

First, as a need stemming from the higher rungs of relative hierarchies of needs. Fulfilling this need is based on participation in one of the social morality games and may be associated with accumulation of moral capital, but may also remain under the subject's autonomous, i.e., habitual control.

Second, as an element and as capital in games played to satisfy a need for recognition. Next, we will look at the practical ways of making use of financial capital, as well as of the mechanisms and techniques for converting capital in order to accumulate moral capital.

Moral capital in action: MDG, SDG and CSR

One of the fundamental ethical issues raised on the international scene is the observance and protection of human rights. This issue also encompasses more detailed problems, such as mitigating extreme poverty, hunger and other forms of suffering. These phenomena are closely linked to the topics of fair distribution of goods, development policy, but also (perhaps above all) to the structure of the global economy and the trade and investment relations between its participants.

Leaving aside the analysis of interrelations between these elements, let us recall that at the highest decision-making level within the United Nations, the Millennium Development Goals (MDG) were adopted in 
2000 and replaced in 2015 by Sustainable Development Goals (SDG). The achievement of these goals was the overarching purpose of cumulative actions carried out between 2000 and 2015 by the international community in response to the most important diagnosed challenges of "global ethics". The MDG included: eradication of extreme hunger and poverty, providing universal primary education, empowering women and promoting gender equality, reducing the child mortality rate, improving the health of pregnant women, combating AIDS, malaria and other diseases, ensuring environmental sustainability, as well as developing and strengthening global partnerships for development.

From the perspective of this paper, it is important to recognize the logic behind the functioning of so-called development aid in light of the actual intentions that govern the actions of the international community. According to the UN General Assembly resolution, the official basis, motivation and justification for actions carried out to achieve the MDG was, among other things, upholding "the principles of human dignity, equality and equity at the global level" (United Nations Millennium Declaration 2000, Article 2), as well as adherence to fundamental values: freedom, equality, solidarity, tolerance, respect for nature, and shared responsibility (Ibidem, Article 6). We assume that these expressions qualify the actions undertaken in order to achieve the MDG as moral acts.

The MDG were to be achieved by 2015 and, as is already known, the majority of them were not achieved ("The Guardian" 2015; cf.: Harris, Provost 2013). Moreover, if not for the considerableimprovement of the economic and social situation in China, which led to a significant positive change in the material situation of more than a billion inhabitants of the Earth, the level of achievement of MDG indicators would be very low. At the same time, the annual costs of the realization of all MDG amounted to less than 200 billion dollars, which constitutes approxi- 
mately $0.5 \%$ of the GDP of the OECD-DAC countries (Investing in Development. A Practical Plan to Achieve the Millenium Development Goals 2005). Considering the above, we assume that achieving the MDG was not a priority for the OECD-DAC countries. At the same time, the international debate increasingly raises the question whether the development of the countries of the Global South really has to depend on extensive financial aid provided by countries of the Global North (cf.: Zarzycki 2015). This is important insofar that revenue leakage and the existence of tax havens mean that countries of the Global South annually lose three times the value of the entire financial aid they receive from developed countries (The Elephant in the Room. How to Finance our Future? 2014).

Significantly, the tax-evading corporations are usually based precisely in those rich countries that are leaders in providing financial aid. For example, 98 out of the 100 largest companies in Great Britain have branches in tax havens. If developing countries could increase their tax revenue, they would largely be able to support their own citizens, protect the environment and implement the other postulates of sustainable development. Using tax revenue to directly fund development is also a better solution than development aid or credit funding insofar that it provides a stable and predictable source of budget revenue. These measures are also subject to much more efficient and far-reaching control, which means that their distribution is more transparent, and thus more effective and compatible with its intended purpose.

The tax system also gives the possibility of internal regulation of the expenditure of funds obtained in accordance with local budget priorities, not in accordance with the guidelines of the countries providing assistance, which often do not match actual needs. Studies performed in the years 2008-2009 by Christian Aid prove that the losses incurred by countries of the Global South because of tax evasion by international corporations total approximately 160 billion dollars annually (Coulby, 
Collinson 2014). For comparison's sake, an effective fight against quantitative malnutrition on a global scale requires financial resources of 50 billion dollars (cf.: Zarzycki 2015). A key element in understanding the mechanisms governing this situation is the fact that developed countries have legal tools enabling them to significantly reduce tax escapes from developing countries (Coulby, Collinson 2014).

An analysis of the postcolonial structure of debt in developing countries, as well as a number of other economic processes, such as the functioning of bilateral investment treaties and the mechanism of investor-to-state dispute settlement (which constitutes an element of those treaties) leads to similar conclusions. As a result of their functioning, the countries of the Global South annually lose sums many times larger than the development aid they receive, while their economies are unable to recover to a point where they could independently and successfully take action to achieve the MDG (now SDG) (Fritz 2015). Considering how low the cost of solving any of the above-mentioned problems would be from the perspective of developed countries, we can provisionally assume that maintaining the current situation remains in line with the political intentions of developed countries.

From the perspective of a pure analysis of financial flows it is clear that money donated by developed countries in the form of aid to fund the development of developing countries returns with a surplus to the developed countries. It should be noted that development measures translate into various types of nonmaterial results, including education, knowledge transfer or technology transfer, which in part distinguishes this type of aid from so-called humanitarian aid. However, for the purposes of this analysis the important issue is that developing countries could acquire all these resources on the free market, paying with means from their own budgets and spending analogous sums as the ones that constitute the volume of development aid. 
Under these circumstances, it is an open question why developed countries provide development aid to developing countries, for what purpose the stream of money flows through the budget of developing countries if thenet balance remains negative. An attempt to explain this phenomenon in terms of the morality games discussed earlier leads to the following conclusions:

(a) the OECD-DAC countries invest financial capital that constitutes a fraction of their GDP into development aid and the realization of MDG (currently SDG); however, due to the abovementioned mechanisms, the overall impact of the economic policy of these countries on the economy of developing countries is unequivocally negative;

(b) this investment is evaluated positively by, for example, inhabitants of the European Union (EU Development Aid and the Millennium Development Goals. Report 2013), to which many of the OECD-DAC countries belong;

(c) thus, capital flow analysis indicates that financial capital translates into moral capital, in accordance with the proposed narrative (in this case, depending on the scope of the presented data: the conclusion is valid within the EU);

(d) furthermore, because of other macroeconomic conditions, in thelong run the entire process does not prove costly in terms of financial capital (the rest of our reasoning remains valid regardless of the validity of this comment, hence it should be treated as a marginal note);

(e) as a result, we are dealing here with highly effective conversion of financial capital, leading to the desired accumulation of moral capital in a sense that is close to Kane's (2001) definition, i.e. image capital as well.

The second example has an analogous structure, so we will discuss it briefly. CSR is a marketing tool, the popularity of which has increased 
significantly in recent years. Nominally, CSR is a concept that compels private market entities to voluntarily take into account social interests, environmental protection and other stakeholders. The aspect of voluntariness plays a fundamental role in this case, because without it we could not legitimately view these actions in moral terms.

We observe a mechanism that is very similar to the activity of the OECD-DAC group. In the case of CSR, we can distinguish the following stages:

a) private market entities invest financial capital representing a fraction of their turnover to fund actions carried out as part of CSR, but as a result of a range of actions performed by these entities as part of their core market activity, the total impact of all their actions is often unambiguously negative (cf.: Centrum CSR.PL 2013; Klein 2010);

b) investment in CSR is generally positively evaluated by managerial staff (cf.: Global Business Barometer 2007), but also by consumers (cf.: Petronzio 2014);

c) thus, analysis of the capital flow indicates that financial capital translates into moral capital, in accordance with the proposed narrative (analogously as in the previous case);

d) moreover, it is suspected in this case, too, that a better image translates into an increase in sales and ultimately, in the long run, leads to a return on investment in financial terms as well (as above, our reasoning remains valid regardless of the validity of this comment, hence it should be treated as a marginal note);

e) as a result, we are once again dealing with highly effective conversion of financial capital that leads to the desired accumulation of moral capital. 
Conclusions - moral capitalism

The essence of the capitalist system is the creation of conditions enabling capital-possessing entities to accumulate more capital. The greater the accumulation of capital, the easier it becomes to accumulate still more. This theoretical, idealistic premise does not take into account many aspects of reality, including e.g. the finite nature of Earth's available material resources.

Historically, both the legitimate forms of acquiring various types of capital and the rules for capital conversion were subject to violent changes. Nowadays, financial capital is the dominant element of social games on a global scale. At the same time, it is a fairly common belief that "trade" in higher values, and therefore the transfer of material capital to games where the satisfaction of higher-level needs is at stake, is somehow unseemly. In this case, money plays a dual role: it acts as a tool of exchange, but also as "autotelic" capital. This, in turn, leads to a cognitive dissonance, which calls for the creation of appropriate externals. A study of this type of techniques used in various sociopolitical circumstances seems to be an important topic for further research.

At the same time, a structural characteristic of the capitalist system is its strong tendency to penetrate all the possible fields of human activity, which can also be described as market niches, and operate within them. The topography of these niches is determined by the demand organized in accordance with the structures of pyramids of relative needs. Although the sphere of morality usually belongs to the top level of needs, and hence is particularly protected against devaluation due to the inflow of capital transferred from the lower levels, it is also among the long-term goals of expansion of financial capital. If capitalism continues to follow the current tendency and maintain its current dynamics 
of development, the structuralisation of values such as justice, responsibility and selflessness in accordance with the logic of commodification seems only a question of time.

The flywheel of expansion thus understood is control over means of production, which must be precisely identified in the case of the commodification of morality. Simultaneously, however, the theory of capital conversion outlined in this work shows that, besides direct sources, the accumulation of moral capital also results from the mechanism of accumulation and subsequent conversion of financial capital. On the other hand, the possibility of direct capital accumulation seems to be the resultant of control and shaping of discourse, i.e. making decisions about current values, as well as the potential to undertake actions qualified by stakeholders as good within the currently valid discourse. This aspect is relatively well recognized (cf.: Foucault 1971).

This phenomenon assumes new, interesting forms in the Internet era. The Internet has caused hyperinflation of information, leading to the dispersal of patterns, which become based on the potential for accumulation of the observers' attention; in other words, communication attractiveness (Zarzycki 2013). In this sense, digital communication tools can easily be utilised, on the one hand, to manipulate values, while on the other hand, they amplify the processes of spectacularization of morality, undermining its credibility at the level of ideas.

Because intentions are, in principle, unmeasurable from a market perspective, moral capitalism thus understood is founded on the consequentialist concept of morality, which is based on valuating the effects of actions, rather than on the emotivist model. There are grounds for formulating the research hypothesis that people suffering from deprivation in regard to lower-level needs will display a tendency to consequentialist evaluations, whereas people suffering from deprivation in regard to higher-level needs will be inclined to make evaluations based 
on emotivist grounds. Verification of this statement seems to beanother interesting research problem.

Thus, one might also say that with the progress of globalization and the development of markets, the processes of commodification cover increasingly higher levels of relative pyramids of needs. As shown by the examples presented in the previous section, the commodification of morality is not just an abstract vision, but an actual social process. In this context, the key question pertains to the architecture of ideologies that enable the legitimization of this form of acquiring moral capital. Further structuring of the field of "morality games" into a shape consistent with the canonical capitalist model is now merely a natural consequence of colonization of the sphere of ethics by the logic of capital.

\section{References}

Berne E. (2016), Games People Play, Penguin Books Ltd, London

Bourdieu P. (1998), Practical Reason: On the Theory of Action, Stanford University Press, Stanford

Bourdieu P. (1984), Distinction. A Social Critique of the Judgement of Taste, Harvard University Press, Cambridge

Bourdieu P., Wacquant L. (1992), An Invitation to Reflexive Sociology, University of Chicago Press- Polity, Chcago

CentrumCSR.PL (2013), Brudny zysk [Dirty Profit], Warszawa, http:// www. csrinfo.org/wp-content/ uploads/ 2016/ 07/raport_brudny-zysk-2013.pdf

Coulby H., Collinson H. (2014), Tax Justice Toolkit. Understanding Tax and Development, European Network on Debt and Development, Brussels The Elephant in the Room. How to Finance our Future? (2014), Dossani S., Ege A. (Eds.), Action Aid International, J ohannesburg, http:/ / www.actionaid.org/ publications/ elephant-room-how-finance-our-future 
EU Development Aid and the Millennium Development Goals. Report (2013), Special Eurobarometer 405, http://ec.europa.eu/commfrontoffice/ publicopinion/archives/ ebs/ebs_405_en.pdf

Foucault M. (1971), Orders of discourse, "Social Science Information" Vol. 10, No. 2, https:// doi.org/ 10.1177/053901847101000201

Fritz T. (2015), International Investment Agreements Under Scrutiny, Traidcraft, Gateshead

Gadamer H.-G. (1986), The Relevance of the Beautiful and other essays, Cambridge University Press, Cambridge

Global Business Barometer (2007), The big issue, Economist Intelligence Unit, an online survey of 1,192 global executives, Nov-Dec 2007

"The Guardian" (2015), What Have the Millennium Development Goals Achieved?, https:// www.theguardian.com/global-development/ datablog/ 2015/jul/ 06/ what-millennium-development-goals-achieved-mdgs

Haidt J . (2012), The Righteous Mind, Pantheon Books- Random House, New York

Harris R., Provost C. (2013), Millennium development goals: big ideas, broken promises?, "The Guardian" September 24

Huizinga J (2016), Homo ludens: A Study of the Play-Element in Culture, Angelico Press, Tacoma

Investing in Development. A practical Plan to Achieve the Millennium Development Goals (2005), UN Report, (Ed.) Sachs J ., United Nations Development Project, Earthscan, London

Kane J . (2001), The Politics of Moral Capital, Cambridge University Press, Cambridge

Klein N. (2010), No logo, Harper Collins Publishers, London

MacLeod J . (1995), Ain't No Makin' It: Aspirations and Attainment in a Low Income Neighbourhood, 2nd ed., Westview Press, Boulder Mills C.W. (2000), The Power Elite, Oxford University Press, New York Nietzsche F. (2009), Thus Spoke Zarathustra, Oxford University Press, Oxford 
Ossowska M. (1971), Social determinants of moral ideas, University of Pennsylvania Press- Routledge \& Kegan Paul, Philadelphia- London/ New York Petronzio M. (2014), Consumers Are Willing to Pay More for Sustainability, Mashable, https:// mashable.com/2014/06/30/ sustainability-consumers/ ?europe $=$ true

Sztompka P. (2015), Kapitał moralny: brakujące ogniwo naszego rozwoju [Moral capital: the missing link of our development], „Rzeczpospolita”, October 5, http:// archiwum.rp.pl/artykul/ 1288282-Kapital-moralny:-bra kujace-ogniwo-naszego-rozwoju.html

Turner V. (1974), Dramas, Fields, and Metaphors: Symbolic Action in Human Society, Cornell University Press, Ithaca

United Nations Millennium Declaration (2000), UN General Assembly Resolution, UNA/Res/55/2, http:/ / www.un.org/ millennium/declaration/ ares552e.htm Zarzycki R. (2013), Information inflation and spectacularization of meanings as sources of hyperreality, (in:) Excess and Lack, (Eds.) Dąbrowska K., Huculak Ł.,J ernajczykJ ., Skowron B., Zakrzewska M., Zarzycki R., Wrocław Academic Hub, Wroclaw

Zarzycki R. (2015), Światowa Organizacja Gtodu [The World Huger Organization], Institute of Global Responsibility, Warszawa 